\title{
REPENSANDO O CUIDADO À MULHER QUE AMAMENTA ${ }^{1}$
}

\section{RETHINKING THE CARE PROVIDED TO NURSING WOMAN}

Maria Tereza H. Godoy ${ }^{2}$ Denize Bouttelet ${ }^{3}$

GODOY, M.T.H.; MUNARI, D. Repensando o cuidado à mulher que amamenta. Rev. Bras. Cresc. Deserte. Hum., São Paulo, 14 (1), 63-68, 2004.

Resumo: Este trabalho tem como objetivo fazer uma reflexão acerca da trajetória das politicas de amamentação no Brasil e da postura que tem sido adorada pelos profissionais de saúde Dente às necessidades da mulher que amamenta. Visa a vivência na prática assistencial destinada a esta clientela e a importância de repensarmos o cuidado dispensado à mulher nessa situação tão singular para ela e para a sua familia. A maternidade, assim como a amamentação, por fazerem parte do ciclo evolutivo das mulheres, representa um momento de crise. Apesar de todas as campanhas de incentivo ao aleitamento materno e do empenho em sua promoção pelos profissionais de saúde. sabe-se que o índice de mães que amamentam ainda é muito baixo. A abordagem do problema está voltada para as vantagens e benef icios do aleitamento materno para a cnança, e pouco se fala das dificuldades emocionais dá mulher que amamenta e de seus conflitos.

Palavras-chave: aleitamento materno; desmame; saúde da mulher; assistência integral à saúde.

\section{INTRODUÇÃO}

A questão da amamentação ou “aleitamento materno” tem sido o nosso foco de interesse há muito tempo, especialmente pela convivência com mulheres que amamentam durante a prática profissional.

Temos observado as várias dificuldades geradas por ocasião do aleitamento materno como, por exemplo, os temores da mulher em ser capaz de amamentar ou não, suas limitações físicas e emocionais em função da própria sobrecarga frente às expectativas de todos diante da necessidade de alimentação do recém-nascido.
Apesar do grande empenho de entidades governamentais e não governamentais na promoção e apoio ao aleitamento materno e dos avanços nas taxas nacionais nas últimas décadas, a situação do aleitamento no Brasil ainda está longe de ser considerada satisfatória (CARVALHAES \& CORRÊA, 2003; REA, 2003; VENÂNCIO, 2003), o que nos leva a questionar a razão desta situação.

Uma dessas questões é a afirmação de que "os discursos técnicos e acadêmicos que embasam os Programas de incentivo ao Aleitamento Materno estão dirigidos ao atendimento das necessidades da criança, não contemplando

1 Pesquisa vinculada ao Núcleo de Estudos e Pesquisa em Saúde integral da Faculdade de Enfennagem da Universidade Federal de Goiás (NEPSI).

2 Professora Auxiliar de Ensino da Faculdade de Enfennagem da Universidade Federal de Goiás. Mestranda do Programa de PósGraduação em Enfennagem da FEN/UFG. Endereço: Rua R 15, nº 86 apto. 903. setor Oeste - Goiania-GO. CEP: 74140-090. E-mail: maitehagen@brturbo.com

3 Professora Doutora/Titular da Faculdade de Enfennagem da Universidade Federal de Goiás. Pesquisadora CNPq. Endereço a ser realizados os contatos: Rua 28 A n 708 apto. 602. Setor Aeroporto CEP: 74075-500. Fones: (062)223-8078 (res.) 209-6180 (profis.) E-mail: denize@fen.ufg.br 
a mulher e suas especificidades" (NAKANO \& MAMEDE, 1999, p. 69). Além disso, as autoras comentam ainda que a amamentação é tida como representação social da mulher, existindo na sociedade uma exaltação de sentimentos prazerosos e do sofrimento, como parte do processo normal do aleitamento.

A amamentação não seria totalmente instintiva no ser humano; em grande parte, tem que ser aprendida e, para ser prolongada com êxito, a maioria das mães que aleitam precisam também de reforço e apoio constante (CARVALHO, 2001; MALDONADO \& CANELLA, 2003), o que reforça a idéia de que "o incentivo ao aleitamento deve incluir também um forte componente de apoio à mulher e uma resposta às suas necessidades" (CARVALHO, 2003). Neste sentido, concordamos com SERAFIM (1999) de que o papel do pai neste processo é de grande relevância, pois, ao se envolver, poderá entender melhor as necessidades da mulher, tornando-se um aliado, um incentivador e um apoio efetivo.

Temos percebido que a maioria das mães que orientamos desistem da prática do aleitamento assim que se depararam com as dificuldades. Esta desistência está associada ao período da apojadura, que ocorre logo depois que elas recebem alta da maternidade. É nesta época onde ocorre a maioria, senão todos os problemas e, quase sempre, as mulheres não recebem o apoio adequado e necessário para que possam conduzir com sucesso a amamentação, daí o desânimo que antecede o fracasso.

Nesse período, o foco do atendimento em saúde volta-se para a criança, chegando inclusive à indicação da suplementação alimentar, quando não da substituição definitiva do leite materno, sem considerar a posição da mulher no seu direito de decidir as questões relativas ao aleitamento materno (MOREIRA \& NAKANO, 2002).

O puerpério é um período de adaptação em que a mulher necessita de apoio, ajuda e cuidados (VINHA, 2000). É justamente nesta época, que os membros da família que participam da convivência com a puérpera, na ânsia de ajudar, muitas vezes tornam a situação confusa, causando mais desgaste e ansiedade à mulher (MALDONADO \& CANELLA, 2003).

Esse processo é algo bem mais complexo do que podemos imaginar por envolver questões não apenas relacionadas à opção da mulher para amamentar, mas bem mais amplas determinadas pelo aspecto biológico e condicionadas pelo contexto sócio-cultural (ALMEIDA, 1999), que devem ainda levar em conta a natureza, a experiência e a diversidade que fazem parte do contexto da mulher que amamenta (SILVA, 2000).
Muitas vezes, no ímpeto de querer promover a saúde, não atentamos para o fato de que podemos estar impondo idéias e conceitos a alguém que já se encontra imersa em conflitos, adquiridos em sua formação e convivência com experiências não muito positivas, sem considerá-las como primeiro ponto a ser trabalhado com a nutriz, antes de iniciarmos nosso discurso em defesa do aleitamento. Além disso, muitas vezes, passamos informações impossíveis de serem compreendidas e seguidas, cheias de duplas mensagens, não considerando variáveis contextuais e valores individuais (SANTOS \& RABINOVICH, 1999).

Nessas ocasiões, deixamos de ouvir a pessoa como um todo, correndo o risco de criar mais um problema, estimulando o sentimento de culpa, além de não garantirmos com a nossa fala que ela vá amamentar o seu filho e ainda dificultamos que ela possa assumir com tranqüilidade a posição de não querer amamentar, um direito que é seu.

Tendo em vista as questões colocadas, temos como objetivo no presente estudo fazer uma reflexão acerca das políticas de amainentação no Brasil e da postura que tem sido adotada pelos profissionais de saúde frente às necessidades da mulher que amamenta, considerando a vivência na prática assistencial destinada a esta clientela e a importância de repensarmos o cuidado dispensado à mulher nessa situação tão singular para ela e para a sua família.

\section{REFLETINDO SOBRE ALGUMAS QUESTÕES DO ALEITAMENTO MATERNO NO BRASIL}

A instituição, em 1981, do Programa Nacional de Incentivo ao Aleitamento Materno tem mobilizado a sociedade brasileira para a promoção da saúde do bebê e o combate à mortalidade infantil.

Aos poucos, os pediatras brasileiros tomaram consciência da importância do aleitamento natural para a saúde das crianças e, com a criação do Comitê Nacional de Aleitamento Materno, iniciou-se a retomada da luta pelo aleitamento materno no Brasil (MARTINS FILHO, 1987; 2002). Esta foi seguida por diversos movimentos governamentais, sociedades de classe, organizações não governamentais, empresas privadas, entre outros, caracterizando um grande avanço e a conquista de diversos resultados, entre os quais iniciativas como a implantação de alojamento conjunto, de bancos de leite humano (ALMEIDA, 1999; REA, 2003).

O desmame precoce, entendido como a interrupção precoce do aleitamento materno an- 
tes dos quatro meses de vida do lactente (ICHISATO \& SHIMO, 2001; KUMMER et al, 2000), em nosso meio ainda é elevado apesar dos altos índices de mortalidade infantil por doenças que poderiam ser evitadas pela prática do aleitamento materno, devido ao valor inigualável do leite humano e de sua importância na prevenção de doenças; na diminuição de incidência dos processos alérgicos; na diminuição de alterações das estruturas orais; e no estabelecimento, com a sua prática, do vínculo afetivo entre mae e filho (CARVALHO, 2001; REA, 2003).

As causas dessa problemática ainda estão sendo estudadas, mas parece que os profissionais de saúde têm aqui sua parcela de responsabilidade, pela falta de apoio dada ao processo da amamentação em toda sua complexidade, uma vez que "a menor parcela de responsabilidade no desmame precoce está com as mães” (CARVALHO, 2001).

De fato, o que temos visto em nossa prática e que tem sido afirmado por estudiosos no assunto é que as pessoas que menos deveriam ser culpadas pelo desmame precoce são as mães (REZENDE, 2000; MARTINS FILHO, 2002). Na realidade, as mulheres deveriam ser estimuladas a amamentar, mas recebendo total apoio para isso, inclusive para optar, conscientemente, em não fazê-lo. Apesar de todo o esforço que temos visto, e de algumas experiências vitoriosas nesse sentido, este é um fato pouco comum em nosso meio.

Os estudos de ALMEIDA (1999) e REA (2003) trazem uma contribuição importante para compreendermos o movimento das políticas nacionais em prol do aleitamento materno desde a década de 70 até os nossos dias.

A década de 70, e o início dos anos 80, foi marcada pelo combate às propagandas de leites substitutivos ao leite materno e pelas orientações da OMS/UNICEF, oriundas da Reunião conjunta dessas organizações sobre a Alimentação Infantil e da Criança Pequena em 1979, cuja medida de maior impacto foi a elaboração de um código de ética para conter o uso de propagandas de produtos que substituiam a amamentação. Esta foi assumida pelo governo brasileiro, através do Instituto Nacional deAlimentação e Nutrição - INAM, que tomou para si a tarefa de veicular a primeira campanha pró amamentação no país. Segundo REA (2003, p. 39), essa decisão política foi acertada na medida em que era visível "uma situação internacional favorável, uma análise adequada da situação e dos determinantes do desmame precoce e a necessidade da volta à amamentação ao nosso meio".

O início dos anos oitenta (1981 a 1986) foi marcado, entre outros aspectos, pelo impacto da grande mobilização social em defesa da causa e de campanhas bem elaboradas e com impacto positivo no aumento do período de permanência da amamentação exclusiva, além da defesa do direito da mãe trabalhadora (ALMEIDA, 1999; REA, 2003).

Os autores salientam que, entre o final da década de oitenta e o início da década de noventa, esboça-se um movimento em direção a mudanças de paradigma para a abordagem do aleitamento, cujas políticas são dirigidas para a articulação entre serviços de saúde, grupos de mães e comunidades. Concomitantemente, ocorre o início de um programa de treinamento para profissionais e de movimentos que envolviam instituições na busca de metas para melhorar o atendimento dos serviços específicos para o atendimento dessa clientela, inclusive a regulamentação de bancos de leite humano (ALMEIDA, 1999; REA, 2003).

Segundo REA (2003), entre os anos de 1996 e 2002, o destaque é dado para a capacitação de profissionais e do incentivo para adesão de instituições no modelo de Hospital Amigo da Criança, criados no período anterior. Além disso, é aspecto marcante também a política em prol do aleitamento exclusivo até os seis meses.

Vale ressaltar que as políticas nacionais em defesa do aleitamento materno foram elaboradas desde o início da década de setenta, articuladas a movimentos internacionais. De certo modo, essa foi uma vantagem para o desempenho do Brasil na luta contra a mortalidade infantil. Questionamos, no entanto, que tais políticas não contemplam as necessidades e direitos da mulher que amamenta, sequer ponderam outras dimensões além da biológica.

Isso, sem dúvida, tem se refletido no modo como os profissionais têm abordado as mães durante o puerpério, desconsiderando muitas vezes suas necessidades e desejos. A dificuldade maior parece estar ligada às questões relacionais, de compreensão do significado e importância da amamentação para as mulheres.

A dimensão técnica, biologicista da amamentação, parece ser a única razão para o cuidado dispensado às mulheres que, na maioria das vezes, são obrigadas a receber passivamente informações, panfetos, aulas, sem serem consideradas nos seus sentimentos e necessidades para o aprendizado da tarefa de amamentar.

Por envolver múltiplas dimensões, esse processo não pode se restringir ao simples repasse de informações ou orientações, mas deve viabilizar também uma abertura para a compreensão de aspectos emocionais, afetivos, culturais e sociais que envolvem a decisão de amainentar e 
de medidas concretas que possam ajudar o binômio mãe-filho nesse processo (MALDONADO \& CANELLA, 2003; CARVALHAES \& CORRÊA, 2003).

Embora não seja possível apontar apenas as limitações relacionadas à formação dos profissionais como entrave na abordagem das mulheres que passam pela experiência de amamentar, essa é, sem dúvida, um dificultados no processo de cuidar dessa clientela, na medida em que as práticas assistenciais, em muitos serviços, andem em descompasso com as necessidades da mulher que irá amamentar.

VENÂNCIO (2003) sinaliza que tais práticas carecem de uma postura mais sensível dos gestores e profissionais sobre essa problemática se, de fato, desejarmos uma atitude transformadora na abordagem dessa mulher, em sua singularidade e complexidade.

\section{OS DESAFIOS DOS PROFISSIONAIS DE SAUDE NO CUIDADO DA MULHER QUE AMAMENTA}

Embora existam investimentos na capacitação dos profissionais de saúde para a abordagem da mulher que amamenta, esse conhecimento é ainda insuficiente na prática da amamentação. São comuns orientações inadequadas que contribuem com o desmame precoce (NEEWMAN, 2001).

A falta de conhecimento por parte dos profissionais de saúde pode ser um dos obstáculos à amamentação por acarretar informações incorretas dadas às mães ou ainda por aumentar o nível de ansiedade em uma situação, por si só, bastante ansiogênica.

Pode ser que o profissional detenha um conhecimento teórico sobre a questão, mas não conhece as reais dificuldades que a mulher enfrenta nessa nova tarefa. Ao desconhecer os processos psíquicos da mulher/mãe e as suas crenças a respeito da amamentação e, ao ignorar tais aspectos, desconhece também que seu discurso pode cair no vazio, o que sinaliza a necessidade de atualização dos profissionais de seus próprios conceitos com relação a essa questão (GIUGLIANI, 1994; ALMEIDA, 1999).

A grande maioria de mulheres não é devidamente preparada para o processo de aleitamento materno. “Amamentar é uma habilidade que necessita ser resgatada, uma prática que precisa ser reaprendida e intensamente apoiada” (RO-ZARIO \& ZAGONEL, 2000, p. 401). Se elas forem simplesmente "bombardeadas" com informações, especialmente as que falam das grandes vantagens do aleitamento para seus filhos como as veiculadas em slogans, lançamos sobre elas uma sobrecarga ainda maior e a total responsabilidade sobre $\mathrm{o}$ ato de amamentar.

Embora a propaganda tenha sido apontada, em um determinado período histórico, como uma grande arma em defesa do aleitamento materno, a sua reprodução mecânica não parece atingir a mulher em suas necessidades. Ao contrário, parece desrespeitá-la na sua capacidade de decidir o que é melhor para si e para seu filho e, ainda, de considerá-la apenas como um meio para se chegar a um fim.

Um desafio aos profissionais de saúde que lidam com essa clientela é entender os limites e desejos da mulher. SILVA (1997, p. 256) afirma, a esse respeito, que "a dinâmica assistencial deve guardar e respeitar as características individuais, propiciando à mulher a busca de alternativas para melhor solucionar as questões enfrentadas (...) Reconhecer as influências contextuais, respeitar as características individuais e projetos de vida de cada uma, não representa destituir a amamentação e o leite materno de seus valores”.

O entendimento da mulher, dentro dessa perspectiva exige, no entanto, uma postura humana do profissional, aspecto nem sempre valorizado pelas instituições que formam os profissionais de saúde. A universidade nesse aspecto tem grande parcela de responsabilidade em mudar esse panorama, já que é dentro dela que são estabelecidos padrões de conhecimentos a serem adquiridos pelos profissionais.

$\mathrm{O}$ que alguns autores apontam quando se referem a essa dimensão do cuidado à mulher que amamenta (SILVA, 1997; ALMEIDA, 1999; VINHA, 2000; REZENDE, 2000; MOREIRA \& NAKANO, 2002; REZENDE et al, 2002) é a necessidade urgente de uma mudança de postura frente à questão do aleitamento que vislumbre, para além da simples tarefa de incentivar a amamentação, compreender a pessoa que é sujeito da situação, no caso a mulher, a partir de outras lógicas, que não apenas a da dimensão biológica.

Essa mudança de postura, na realidade, é uma exigência para que o processo de humanização do cuidado em saúde, uma das idéias centrais dos programas governamentais e de ONGs de Incentivo ao Aleitamento Materno, na atualidade, seja efetivo.

Esse fato requer que a formação do profissional para esse cuidado deva ser uma prerrogativa inicial. Segundo NOGUEIRA-MARTINS (2001), é fundamental ao profissional de saúde, na atualidade, ser sensibilizado durante a sua for- 
mação, ou através de projetos de educação permanente quando já profissional, para se perceber como sujeito do cuidado do outro e, dessa forma, não poder se esquivar da tarefa de compreender a natureza do cuidado que irá prestar.

Talvez com uma postura mais aberta para a sua própria humanidade, o profissional possa ser mais sensível à mulher que amamenta e entender as suas necessidades, escolhas e desejos.

Nesse sentido, a Enfermagem tem sido uma categoria profissional que tem empenhado grande esforço em conhecer melhor os meandros desse processo delicado que é a amamentação, para de fato cuidar da mulher, do bebê e da formação dos seus profissionais.

MOREIRA \& NAKANO (2003, p. 689), por exemplo, sugerem que a questão da amamentação seja tratada sob o enfoque dos direitos reprodutivos, por essa perspectiva possibilitar " 0 reconhecimento da singularidade e da individualidade da mulher, integrando assim, o processo de aleitamento à própria história de vida da mãe. Isto significa uma outra lente através da qual serão desenvolvidas ações de incentivo ao aleitamento materno".

O mérito dos estudos gerados dentro da perspectiva da enfermagem está alicerçado na compreensão da experiência da amamentação para a mulher, articulada com estudos de outros profissionais que ajudam a descobrir que esta prática é construída no cotidiano, no ambiente natural, social e cultural no qual ela está inserida por inteiro e envolve diversos papéis e atividades desempenhadas por ela (SILVA, 1997; 2000).

\section{PARAFINALIZAR}

Da aproximação feita sobre a problemática do aleitamento materno no Brasil, destacamos que a dimensão da saúde e dos direitos da mulher que amamenta são pouco valorizadas, o que nos aponta para a necessidade de estudos que proponhain intervenções que abordem este aspecto na assistência, cuidando igualmente da saúde da criança e da mãe.

Acreditamos que, através da formação dos profissionais de saúde, alicerçadas em outras perspectivas de pensar a questão da amamentação, o cuidado à mulher pode se tornar menos opressor, discriminatório e excludente, como defendem MOREIRA \& NAKANO (2003). De igual forma, políticas que venham também considerar essa dimensão nas suas propostas poderão viabilizar possíveis transformações na assistência a essa clientela.

É fundamental aos profissionais de saúde em formação, e àqueles envolvidos na assistência a mulher que amamenta, um olhar mais critico a respeito de sua prática profissional, para não reproduzirem simplesmente discursos cristalizados sobre essa questão e não se acomodarem na postura de meros repetidores de saberes que parecem não atender às necessidades das mulheres e dos seus filhos.

A Universidade, por sua vez, tem um papel fundamental nesse processo de sensibilização dos profissionais, uma vez que é a grande responsável tanto em produzir novos conhecimentos e tecnologias quanto em contribuir efetivamente para a formação de profissionais críticos, reflexivos e conscientes da sua tarefa de cuidar, fundamentado na ética da vida.

\begin{abstract}
The objective of this work is lo reflect on lhe issues of breast-feeding policies in Brazil and how health professionals have behaved towards lhe nursing woman's needs. Both maternity and breast-feeding are part of a woman's evolutionary cycle, and represent a moment of crisis. In spite of ali lhe campaigns to promote breast-feeding and the encouragement given by health professionals, it is known that nursing mothers are still a minority. It was possible to perceive that the problem is being approached from the standpoint of the advantages and benefits breastfeeding provides for the children, and very little is said about the emotional difficulties and conflicts the nursing woman undergoes.
\end{abstract}

Key-words: breast-feeding; weaning; woman's health; Comprehensive Health Care.

\section{REFERÊNCIAS}

Almeida JAG Amamentação: um híbrido natureza cultura. Rio de Janeiro: Editora Fiocruz, 1999.

Carvalhaes MABL, Corrêa CRH. Identificação de dificuldades no inicio do aleitamento materno mediante aplicação de protocolo. Jornal de Pediatria. Rio de Janeiro, 2003, 79(1): 13-20.
Carvalho GD. Amamentação: uma avaliação abrangente. [online] http://www.aleitamento.org.br/gabi2.htm. [acesso em 26 dez. 2001].

Carvalho MR. Planejando cidades amigas da amamentação. [online] http://www.aleitamento.org.br/ cidades.htm [acesso em 08 out. 2003]. 
Giugliani ERJ. Amamentação: como e porque promover. Jomal de Pediatria. Rio de Janeiro,1994, 70(3): 138-47.

Ichisato SM, Shimo AKK. Aleitamento materno e as crenças alimentares. Revista Latino-americana de Enfermagem. Ribeirão Preto,2001, 9(5): 70-76.

Kummer SC, Giugliani ERJ, Susin LO, Jacson LF, Lermen NR, Wu VYJ, Santos L, Caetano MB. Evolução do padrão do aleitamento materno. Revista de Saúde Pública. São Paulo, 2000, 34(2): 143-148.

Maldonado MT, Canella P. Recursos de relacionamento para professores de saúde: a boa comunicação com clientes e seus familiares em consultórios, ambulatórios e hospitais. Rio de Janeiro: Reichmann, Affonso Editores Ltda., 2003.

Martins Filho J. Como e porque amamentar. $2^{\text {a }}$ ed. São Paulo: Sarvier, 1987.

Martins Filho J. Evolução do aleitamento materno no Brasil. [online] http://www.epub. org.nutriweb [acesso em 15 set 2002].

Moreira KFA, Nakano AMS. Aleitamento materno: intuitivo? Natural: O paradigma biológico $\mathrm{X}$ os direitos reprodutivos em discussão. Revista Brasileira de Enfermagem. Brasília, 2002, 55(6): 685-90.

Nakano AMS, Mamede MV. A prática do aleitamento materno em um grupo de mulheres brasileiras: movimento de acomodação e resistência. Revista Latino-americana de Enfermagem. Ribeirão Preto, 1999, 7(3): 69-76.

Neewman J. Amamentação e culpa. [online] http:/ / www.aleitamento.org.br/guilt.htm. [acesso em 26 dez. 2001].

Nogueira-Martins MCF. Humanização das relações assistenciais: a formação do profissional de saúde. São Paulo: Casa do Psicólogo, 2001.

Rea MF. Reflexões sobre a amamentação no Brasil: de como passamos a 10 meses de duração. Cadernos de Saúde Pública. Rio de Janeiro, 2003, 19 (suppl. 1): 37-45.
Rezende MA. Amamentação: uma necessária mudança de enfoque. Revista da Escola de Enfermagem da USP. São Paulo, 2000, 34(2): 226-9.

Rezende MA, Sigaud CHS, Verissimo MDLOR, Chiesa AM, Bertolozzi MR. O processo de comunicação na promoção do aleitamento materno. Revista Latino-americana de Enfermagem. Ribeirão Preto, 2002, 10(2): 234-8.

Rozário OS, Zagonel, Proposta de cuidar com enfoque educativo às mães em aleitamento materno. Revista Brasileira de Enfermagem. Brasilia, 2000, 53(3): 401-9.

Santos-Oliveira NGD, Rabinovich EP. Estudo comparativo da amamentação em casas e em creches paulistanas e no interior do Piauí. Revista Brasileira de Crescimento e Desenvolvimento Humano. São Paulo, 1999, 9(1): 20-5.

Serafim D. Estudo das opiniões do pai sobre o aleitamento materno e sua participação neste processo. Revista Brasileira de Crescimento e Desenvolvimento Humano. São Paulo, 1999, 9(1): 9-19.

Silva IA. Amamentar: uma questão de assumir riscos ou garantir benefício. São Paulo: Robe Editorial, 1997.

Silva IA. Desvendando as faces da amamentação através da pesquisa qualitativa. Revista Brasileira de Enfermagem. Brasília, 2000, 53(2): 241-9.

Venâncio SI. Dificuldades para o estabelecimento da amamentação: o papel das práticas assistenciais das maternidades. Jornal Pediatria. Rio de Janeiro, 2003 Fev 79(1): 1-2.

Vinha VHP. O livro da amamentação. São Paulo: CLR Balieiro, 2000. 